\title{
Epidemiological, Clinical and Etiological Aspects of Sciatica in Hospital Setting, CNHU-HKM Cotonou
}

\author{
Constant Kodjo Adjien 1,2*, Dieudonné Gnonlonfoun ${ }^{1,2}$, Cyriaque Dochamou ${ }^{2}$, \\ Accrombessi Donald ${ }^{2}$, Dismand Houinato ${ }^{1,2}$
}

${ }^{1}$ Neurology Teaching and Research Unit, Faculty of Health Sciences, University of Abomey Calavi, Cotonou, Benin

${ }^{2}$ Neurology University Clinic, CNHU HK-Maga Teaching Hospital, Cotonou, Benin

Email: ^adjienconstant@gmail.com

How to cite this paper: Adjien, C.K., Gnonlonfoun, D., Dochamou, C., Donald, A. and Houinato, D. (2018) Epidemiological, Clinical and Etiological Aspects of Sciatica in Hospital Setting, CNHU-HKM Cotonou. Neuroscience \& Medicine, 9, 171-179.

https://doi.org/10.4236/nm.2018.94017

Received: October 4, 2018

Accepted: November 24, 2018

Published: November 27, 2018

Copyright $\odot 2018$ by authors and Scientific Research Publishing Inc. This work is licensed under the Creative Commons Attribution International License (CC BY 4.0).

http://creativecommons.org/licenses/by/4.0/

\begin{abstract}
Sciatica, mostly clinical-based diagnosis, is a potentially debilitating condition as a result of disco-radicular conflict between $\mathrm{L}_{4}$ and $\mathrm{L}_{5}$ or $\mathrm{L}_{5}$ and $\mathrm{S}_{1}$. This study aims at describing the epidemiological, clinical and etiological aspects of sciatica in Hubert Koutoukou Maga Teaching Hospital (CNHU-HKM) of Cotonou. It was a prospective, descriptive and analytical study conducted in CNHU-HKM Cotonou neurology department from $1^{\text {st }}$ January to $30^{\text {th }}$ June 2016. The study population comprised 115 low back pain patients seen in consultation. Data collection was carried out through a standard information sheet with socio-demographic, clinical, para-clinical, etiological and therapeutic data. Epi data 3.1 was used for data entry and Stata11 for processing. Frequency of sciatica was $18.6 \%$, with $95 \%$ CI [11.5\% - 25.7\%]. The study population age ranged from 29 to 73 years, with $52 \pm 16$ as mean value, while sex ratio was estimated at 0.6 . Bilateral sciatica representing $53 \%$ was present in $\mathrm{L}_{5}$ and $\mathrm{S}_{1}$ nerve roots in $44.4 \%$ of cases. It was exacerbated in prolonged standing (24.4\%) and relieved in supine position (44.3\%), with paresthesia (59.1\%) and intermittent radicular claudication (40.9\%). Spinal osteoarthritis was the most prevalent etiology (47\%). Sciatica is becoming increasing prevalent and should be regarded as problem of health concern.
\end{abstract}

\section{Keywords}

Sciatica, Prevalent, Cotonou

\section{Introduction}

Sciatica is a potentially debilitating ubiquitous condition. It is a common diag- 
nosis in patients seen in neurology and primary care consultations [1]. This pain originating from the back radiates in the pelvic limb through $\mathrm{L}_{5}$ or $\mathrm{S}_{1}$ spine segment. It settles down as a result of disco-radicular conflict between $\mathrm{L}_{4}$ and $\mathrm{L}_{5}$ or $\mathrm{L}_{5}$ or $\mathrm{S}_{1}$. Sciatica diagnosis is mainly clinical. Plain radiography and, computed tomography (CT) and magnetic resonance imaging (MRI) are used to assess sciatica etiology. Herniated disc is the major cause of severe, chronic or recurrent lower back pains [2] [3].

Frequency of sciatica in the general population ranges from $14 \%$ to $45 \%$ [4]. In France, it is estimated between 5\% and 10\% [5]. In sub-Saharan Africa, particularly in Nigeria, $16.4 \%$ of the general population suffered from sciatica in 2007 [3]. In Benin, in a study conducted between 1994 and 1996 by AVIMADJE et al., sciatica accounts for $10.1 \%$ of rheumatic diseases in patients seen in consultation at CNHU-HKM Cotonou [4]. Occupation-based analysis helps to determine occupation-related physical, psychological and personal risk factors associated with sciatica [6].

In Benin, few studies were conducted on sciatica in hospital setting. However, no research has ever been carried out in neurology department, though the unit handles a significant proportion of sciatica cases. Hence, this study was initiated and conducted so as to fill this gap. The key objective was to assess the epidemiological, clinical and etiological aspects of sciatica in the neurology department of Hubert Koutoukou Maga (HKM) Teaching Hospital (CNHU) in Cotonou.

\section{Study Methods}

It was a cross sectional, prospective, descriptive and analytical study conducted from $1^{\text {st }}$ January 2016 to $30^{\text {th }}$ June 2016 in the University Clinic of Neurology, CNHU HK Maga of Cotonou on sciatica patients seen in consultation over the study period. All patients meeting the inclusion criteria were systematically included in the study. Individuals excluded comprised patients with no complaints of sciatica, patients unable to describe the complaint and those who declined taking part in the study. Data collection was carried out through a standard information sheet with socio-demographic, clinical, para-clinical, and etiological data. Epi data 3.1 was used for data entry and Stata 11 for processing.

One hundred and fifteen patients were systematically included in the study.

\section{Outcomes}

Overall, of 618 patients seen in consultation during the study period, 115 (18.6\%) individuals including 44 men were involved in this study. Their age ranged from 29 to 73 years with $52+/-16$ as mean value. Individuals aged 40 to 59 and those over 60 years of age were in highest proportion i.e. $49.6 \%$ and $27.8 \%$ respectively. The respondents' features are highlighted in Table 1.

Of the 115 respondents, 61 (53.1\%) suffered from bilateral sciatica, 32 (27.8\%) right lateral sciatica and $22(19.1 \%)$ left lateral sciatica. The pain was topographically bilateral $\left(\mathrm{L}_{5}\right.$ and $\mathrm{S}_{1}$ ) with 51 individuals $(44.4 \%)$, unilateral $\mathrm{L}_{5}$ with 34 indi- 
viduals (29.6\%) and unilateral $S_{1}$ with 13 patients (11.3\%). The development of sciatica was acute ( $<1$ month), sub-acute ( 1 - 3 months) and chronic ( $>3$ months) in $20 \%, 14.8 \%$ and $65.2 \%$ of cases respectively. Patients reported severe (53\%), mild (31.3\%), light (4.4\%) and normal (11.3\%) pain. Prolonged standing and prolonged sitting were the most common triggering factors in $19.1 \%$ and $18.3 \%$ of the cases respectively. Twenty-eight patients (24.3\%) reported increased pain during prolonged standing followed by 26 patients $(22.4 \%)$ during prolonged sitting and $26(22.4 \%)$ when walking. Supine position was the most relieving factor in 51 patients (44.4\%). Paresthesia stands out as the most commonly associated symptom (59.1\%), followed by intermittent claudication (40.9\%), sphincter disorders (03.5\%) and muscleatrophy (02.6\%). The physical examination revealed Doorbell sign in 49 patients (42.6\%), positive straight leg raising test in 63 individuals (54.8\%) with $13 \%$ of them feeling pains at an angle below $30^{\circ}$ and $31.3 \%$ when an angle is above $60^{\circ}$. Over half patients $(51.3 \%)$ had a Lasègue sign between $30^{\circ}$ and $60^{\circ}$. Plain radiography was the most performed paraclinical examination: 63 patients (54.78\%), followed by lumbar spine CT scan with 21 patients (18.26\%). The clinical and paraclinical features of these individuals are highlighted in Table 2 and Table 3. Degenerative injuries account for the major etiology in a proportion of $47 \%$. These statistics are summarized in Figure 1. Sex was the only feature significantly associated with sciatica $(\mathrm{p}=$ 0.020). Age, occupation, level of education and BMI were not associated with sciatica, $\mathrm{p}=0.293 ; \mathrm{p}=0.363 ; \mathrm{p}=0.819 ; \mathrm{p}=0.211$ respectively.

Factors associated with the onset of sciatica in this study are summarized in Table 1.

Table 1. Respondents' socio-demographic features, Cotonou, 2016.

\begin{tabular}{cccc}
\hline Age & Sciatica (N) & Percentage (\%) & p \\
$20-39$ & 26 & 22.6 & \\
$40-59$ & 57 & 49.6 & 27.8 \\
$\geq 60$ & 32 & & 0.020 \\
Sex & & 38.3 \\
Male & 44 & 61.7 & \\
Female & 71 & \\
Occupation & & 20.9 \\
Office clerk & 24 & 08.7 \\
Craftsman & 10 & 16.5 \\
Self-employed & 19 & 02.6 \\
Student & 03 & 20.9 \\
Housewife & 24 & 20.0 \\
Pensioner & 23 &
\end{tabular}




\section{Continued}

\begin{tabular}{cccc}
\hline Health practitioner & 12 & 10.4 & \\
Educational level & 17 & 14.8 & 0.819 \\
uneducated & 29 & 25.2 & \\
Primary & 29 & 25.2 & \\
Secondary & 36 & 31.3 & \\
Higher & & & \\
BMI & 7 & 06.1 & \\
Underweight & 52 & 45.2 & \\
Normal & 38 & 33.0 & \\
Overweight & 18 & 15.6 & \\
Obesity & & & \\
\hline
\end{tabular}

Table 2. Respondents' functional and clinical features, Cotonou 2016.

\begin{tabular}{|c|c|c|}
\hline Features & $\begin{array}{l}\text { Total } \\
(\mathrm{N})\end{array}$ & $\begin{array}{l}\text { Percentage } \\
\text { (\%) }\end{array}$ \\
\hline \multicolumn{3}{|l|}{ Pain topography } \\
\hline $\mathrm{L}_{5}$ and $\mathrm{S}_{1}$ & 51 & 44.4 \\
\hline $\mathrm{L}_{5}$ & 34 & 29.6 \\
\hline $\mathrm{S}_{1}$ & 13 & 11.3 \\
\hline Truncated & 17 & 14.7 \\
\hline \multicolumn{3}{|l|}{ pain severity } \\
\hline Severe & 61 & 53 \\
\hline Mild & 36 & 31.3 \\
\hline Light & 05 & 4.4 \\
\hline Normal & 13 & 11.3 \\
\hline \multicolumn{3}{|l|}{ Development } \\
\hline Acute ( $<1$ month) & 23 & 20.0 \\
\hline Sub-acute (1 - 3 months) & 17 & 14.8 \\
\hline Chronic (>3 months) & 75 & 65.2 \\
\hline \multicolumn{3}{|l|}{ Triggering factors } \\
\hline Prolonged standing & 22 & 19.1 \\
\hline Prolonged sitting & 21 & 18.3 \\
\hline Heavy lifting & 20 & 17.4 \\
\hline Spine injury & 19 & 16.5 \\
\hline Briskspinal movements & 10 & 8.7 \\
\hline None & 23 & 20.0 \\
\hline \multicolumn{3}{|l|}{ Aggravating factors } \\
\hline Prolonged standing & 28 & 24.3 \\
\hline
\end{tabular}




\section{Continued}

\begin{tabular}{ccc}
\hline prolonged sitting & 26 & 22.6 \\
Walking & 26 & 22.6 \\
Efforts & 19 & 16.5 \\
Change in posture & 06 & 05.2 \\
None & 10 & 11.5 \\
Relieving factors & & \\
Change in posture & 15 & 13.1 \\
Prolonged sitting & 06 & 05.2 \\
Prolonged standing & 07 & 06.1 \\
Walking & 20 & 17.4 \\
Efforts & 01 & 0.9 \\
Supine position & 51 & 44.4 \\
None & 15 & 13.0 \\
Associated signs & & 03.5 \\
Paresthesia & 68 & 59.1 \\
Intermittent claudication & 47 & 40.9 \\
Sphincter disorders & 04 & 02.6 \\
Muscle atrophy & & \\
\hline & & \\
\hline
\end{tabular}

Table 3. Respondents' clinic-physical features, Cotonou 2016.

\begin{tabular}{ccc}
\hline Features & $\begin{array}{c}\text { Population size } \\
(\mathrm{N})\end{array}$ & $\begin{array}{c}\text { Percentage } \\
(\%)\end{array}$ \\
\hline Spine examination & & 7.8 \\
Hyperlordosis & 9 & 14.8 \\
Scoliosis and habit scoliosis & 17 & 36.5 \\
Limitation and spinal stiffness & 42 & 42.6 \\
Doorbell sign & 49 & \\
Pelvic limbs examination & & 24.4 \\
Sensory deficit & 28 & 20.0 \\
Motor dysfunction & 23 & 23.5 \\
Deep tendon reflex (DTR) & 27 & 17.4 \\
Prone knee bent (PKB) & 20 & 54.8 \\
Lasègue test & 63 & \\
Lasègueangle & & 13.0 \\
30 & 15 & 51.3 \\
[30 - $60^{\circ}$ ] & 59 & 31.3 \\
$>60^{\circ}$ & 36 & 04.3 \\
Negative & &
\end{tabular}




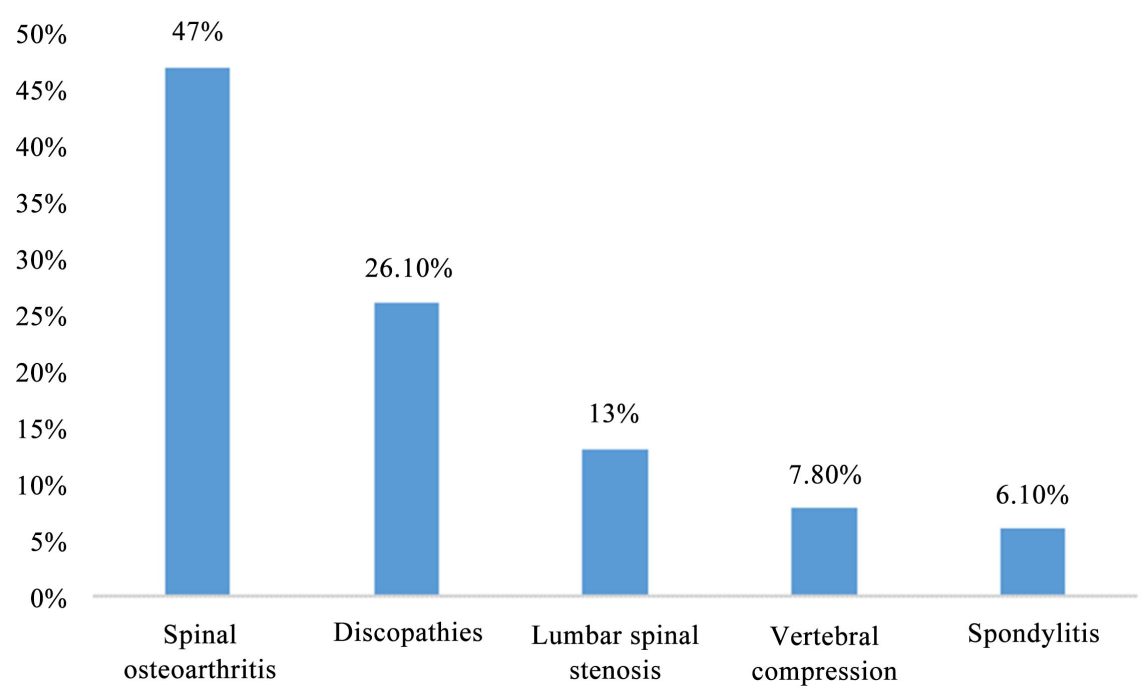

Figure 1. Sciatica patients classification according to etiological data, Cotonou, 2016.

\section{Discussion}

Frequency of sciatica in CNHU-HKM of Cotonou was $18.6 \%$.

The literature highlights wide variability in frequency of sciatica in hospital setting [1] [2] [3]. In Benin, AVIMADJE et al. reported in 1999 that, sciatica accounted for $10.1 \%$ of rheumatic diseases in patients seen in consultation at CNHU-HKM [4]. In Nigeria, $16.4 \%$ of the general population suffered from sciatica in 2007. Therefore, our study result was higher than records reported in the literature. This leads to the conclusion that sciatica is becoming increasing prevalent with time. Postures adopted at worksations, prolonged sitting, prolonged standing, jerking on motorcycle due to poor roadconditions affect the frequency of sciatica.

The study population age ranged from 29 to 73 years, with $52 \pm 16$ as mean value. Respondents aged 40 to 59 and those above 60 were prevalent, representing $49.6 \%$ and $27.8 \%$ respectively. These results show that sciatica affects both the youth and the elderly. The working population is the most vulnerable to this medical condition, as a result of poor postural hygiene in daily and professional tasks. MILLOGO [7] Bobo-Dioulasso reported 46 asmeanage, which is slightly lower than ours. In France, CURRALADAS [6] noted that the most affected age range was 40 - 50 years, with extremes values ranging from 18 to 76 years. Thus, sciatica mostly affects the middle-aged population, primarily those in their forties and sixties.

In our study, females outnumbered males, with an estimated sex ratio $(M / F)$ of 0.6 .

Other authors also noted female prevalence: AVIMADJE et al. [4] and MIJIYAWA et al. [8] with a sex ratio of 0.69 and 0.7 respectively. Such female prevalence of sciatica could be explained by a number of factors, especially household chores, maternity, overweight and development of women related work. 
No sex prevalence was reported in the studies conducted by VALLS et al. [9]. However, DELACAMBRE et al. [10] VALAT et al. [11] outlined male prevalence of sciatica and explained it by the fact that men put more strain on their spine in their daily activities and behaviors.

In our study, sciatica affected several sectors of activities, chiefly housewives and office clerks. This observation can be justified by the constraints of household chores which require adopting awkward postures, resulting in gradual degeneration of the spine. Similarly, for office clerks, prolonged sitting is a cause of dorsopathy.

Our results are consistent with those of COSTE et al. [12] who discovered that sciatica affects workers engaged in active physical work and unskilled workers who endureback-breaking activities, prolonged postures and briskspinal movement, recurrent heavy lifting and exposure to vibration.

In our study, sciatica bi-radicular injury is prevalent (44.3\%). In $29.6 \%$, sciatica affects $L_{5}$ nerve root against $11.1 \%$ for $S_{1}$. The various studies conducted highlight diverging results, although no explanation was provided to justify either of the root injuries. MIJIYAWA et al. [13] reported $\mathrm{L}_{5}$ root nerve injury prevalence. As for VALLS et al., they noted $\mathrm{S}_{1}$ injury (41.9\%) against $\mathrm{L}_{5}$ (37.1\%) [9].

In our study, $53 \%$ and $31.3 \%$ of the patients reported severe and mild pain respectively. Pain is a subjective symptom and many factors, especially psychology, determine its assessment. CHEOUR et al. observed severe and mild pain in $57 \%$ respectively [14].

Triggering factors mainly include prolonged standing (19.1\%), prolonged sitting $(18.3 \%)$, and heavy lifting (17.4\%). However, the prevalent aggravating factor was prolonged standing (24.3\%). As a relieving factor, supine position was much more recorded (44.4\%).

YOUNES et al. reported high proportions of pain triggering factors (85.5\%) [15], as well as VALLS et al. (73\%) [9]. It should be noted that all these factors are determined by the daily activities of patients whether physical, strenuous or not, the poor conditions of our roads and observance or non-observance of postural hygiene.

Symptoms associated with pain were characterized by high paresthesia (59.1\%) followed by intermittent claudication (40.9\%). All the etiologies of sciatica result in painrelated paresthesia. Claudication of the sciatic nerve is much more observed in lumbar spinal stenosis. ONIANKITAN et al. in Togo, reported higher proportions, $84 \%$ of claudication of the sciatic nerve and $70 \%$ of paresthesia associated with pain [16]. On the other hand, BEJIA et al. reported relatively low proportions of paresthesia (37\%) and intermittent claudication (30\%) [17].

The patients were positive to Doorbell sign (42.6\%), followed by spinal stiffness (36.5\%). Higher proportions were found in the study carried out by BEJIA et al. (Doorbell sign (70.3\%) and spinal stiffness (89.1\%) [17] while VALLS et al. recorded relatively low proportions of $15.6 \%$ for the former and $79.3 \%$ for the 
latter [9].

Sensory and motor testing including other neurological maneuvers conducted on all patients revealed Lasègue sign in $54.8 \%$ of the cases and sensory disorder in 24.4\%. Regarding Lasègue sign, VALLS et al. had similar results to ours (54\%) [9]. CHEOUR et al. reported 34\% sensory disorders and 36.7\% Lasèguesign [14].

We noted that $13 \%$ of patients felt pains at an angle below $30^{\circ}$ and $31.3 \%$ when an angle is greater than $60^{\circ}$. Over half of the patients (51.3\%) had Lasègue sign between $30^{\circ}$ and $60^{\circ}$.

Assessment of Lasègue angle involves several factors depending on the examiner, the size of a herniated disc or peri-spinal ligamentous laxity. Indeed, a variety of reports are conducted on Lasèguesign positivity. BEJIA et al. noted that $16.2 \%$ of their patients recorded Lasègue angle below or equal to $60^{\circ}$ [17].

Of all para-clinical examinations, plain radiography was the most performed by the patients, representing $54.8 \%$. This standard X-ray examination is available and affordable to the vast majority of patients, whereas scan $(18.3 \%)$ is less available and geographically and financially limited.

Spinal osteoarthritis was etiologically prevalent (47\%), followed by discopathy (26.1\%), lumbar spinal stenosis (13\%), spinal compression (7.8\%) and spondylitis $(6.1 \%)$. Different proportions were recorded by SONHAYE et al. in Togo where they reported in their lumbar spine CT scan-based study conducted in 2014, 11\% for arthritis, 34\% forherniated disc and 23\% for disc protrusion [18]. This represents higher aggregate proportions than that of discopathy (herniated disc and protruding disc) in our case. This could be explained by the low number of patients who could afford lumbar CT scan in our study; this examination being more recommended for diagnosis of herniated disc.

\section{Conclusion}

Sciatica is an increasing prevalent condition which stands out as a major reason for neurological consultation. There is need for better understanding to enable preventive care and proper management so as to prevent complicated debilitating forms of sciatica.

\section{Conflicts of Interest}

The authors declare no conflicts of interest regarding the publication of this paper.

\section{References}

[1] Grellier, P. (1995) Sciatique, cruralgie et canal lombaire étroit. In: Decq, P. and Keravel, Y., Eds., Neurochirurgie, Edition Ellipses, AUPELF/UREF, Paris, 394-405.

[2] Boco, V., Padonou, J.L. and Avode, D.G. (1997) La lombosciatique au long cours au CNHU de Cotonou: Diagnostic et traitement. Le Bénin Médical, 6, 4548.

[3] Curraladas, J. (1996) Enquête chez les lombosciatiques opérées. Kinésithérapie Scientifique, 361, 7-13.

[4] Avimadje, A.M., Goupille, P., Attolou, V., Djrolo, F., Amoussou-Guenou, D. and 
Sossa, J.C. (1999) Facteurs de risque de la lombalgie par discopathie dégénérative lombaire au Bénin. Le Bénin Médical, 12-13, 91-95.

[5] Clarisse, J., Cotten, A., Chastanet, P., Singer, B. and Assaker, R. (1995) Bilan Radiologique d'une sciatique opérée et récidivante. Radiological Journal of the College of Education Postgraduate Radiology (CEPUR), 15, 50-56.

[6] Agence Nationale Pour Le Developpement De L'Evaluation Medicale (1995) Lombosciatique commune, sciatique commune, sciatique vertébrale, stratégie diagnostique et thérapeutique Recommandation et Référence Médicales. Tome 1, Paris, 99-124.

[7] Millogo, A., Bamouni. A.Y., Taoko, A., Ki-Zerbo, G.A., Sawadogo, A.B. and Yameogo, A. (1999) Lombosciatiques: Profil radioclinique et étiologique au Centre Hospitalier de Bobo-Dioulasso. Médecine d Afrique Noire, 46, 375-378.

[8] Mijiyawa, M., Oniankitan, O., Kolani, B. and Koriko, T. (2000) La lombalgie en consultation hospitalière à Lomé (Togo) [Low Back Pain in Hospital Outpatients in Lomé (Togo)]. Revue du Rhumatisme, 67, 914-920.

https://doi.org/10.1016/S1169-8330(00)00033-8

[9] Valls, I., Saraux, A., Goupille, P., Baron, D., Golff, L.P. and Khoreichi, A. (2001) Existe-T-Il des critères prédictifs de la réalisation d'un geste radical au décours d'une hospitalisation pour lombosciatique. Revue du Rhumatisme, 68, 57-66. https://doi.org/10.1016/S1169-8330(00)00082-X

[10] Delacambre, B., Thevenon, A. and Chastanet, P. (1996) Les discopathies lombaires. Review of the Practitioner, 36, 713-723.

[11] Valat, J.P., Goupille, P., Rozenberg, S. and Urbinelli, R. (2000) Indice prédictif de l'évolution chronique des lombalgies aigues. Elaboration par l'étude d'une cohorte de 2487 patients. Revue du Rhumatisme, 67, 528-535. https://doi.org/10.1016/S1169-8330(00)00007-7

[12] Coste, J. and Paolaggi, J.B. (1989) Epidémiologie des lombalgies: Connaissances actuelles et perspective. Journal of Rheumatology and Osteoarticular Diseases, 58, 861-867.

[13] Mijiwama, M.A., Kounouvi, K., Bellow, A. and Dory, P. (1992) Pathologie dégénérative du rachis lombaire en consultation hospitalière à Lomé. Journal of Rheumatology and Osteoarticular Diseases, 52, 797-800.

[14] Cheour, E., Hamdi, W., Tekaya, R., Hamza, S., Sellami, S. and Khosrof, M. (2007) Les lombosciatiques communes du sujet âge. The Medical Tunisia, 85, 549-552.

[15] Younes, M., Bejia, I., Aguir, Z. and Letaief, M. (2006) Prévalence et facteurs associés à la sciatique commune dans une population urbaine Tunisienne. Revue $d u$ Rhumatisme, 73, 927-931. https://doi.org/10.1016/j.rhum.2005.10.024

[16] Oniankitan, O., Magnan, A., Flanyo, E. and Mijiyawa, M. (2007) Le canal lombaire rétréci en consultation rhumatologique à Lomé. Med. Trop Tropical Medicine, 67, 263-266.

[17] Bejia, I., Younes, M., Zrour, S. and Touzi, M. (2004) Les facteurs associés à l'évolution de la sciatique commune. Revue du Rhumatisme, 71, 1180-1185. https://doi.org/10.1016/j.rhum.2004.01.008

[18] Sonhaye, L., Tchaou, M., Amadou, A., Assih, K., Kolou, B., Gbande, P., Assogba, K., Adjenou, K. and N'dakena, K. (2014) Aspects étiologiques des lombosciatiques à la tomodensitométrie au Togo: A propos de 166 cas. Rev. CAMES Health, 2. 